\title{
A cross-sectional survey to evaluate knowledge, attitudes and practices (KAP) regarding seasonal influenza vaccination among European travellers to resource-limited destinations
}

\author{
Alena Pfeil ${ }^{1}$, Margot Mütsch*2, Christoph Hatz² and Thomas D Szucs 3
}

\begin{abstract}
Background: Influenza is one of the most common vaccine-preventable diseases in travellers. By performing two crosssectional questionnaire surveys during winter 2009 and winter 2010 among European travellers to resource-limited destinations, we aimed to investigate knowledge, attitudes and practices (KAP) regarding seasonal influenza vaccination.

Methods: Questionnaires were distributed in the waiting room to the visitors of the University of Zurich Centre for Travel' Health (CTH) in January and February 2009 and January 2010 prior to travel health counselling (CTH09 and CTH10). Questions included demographic data, travel-related characteristics and KAP regarding influenza vaccination. Data were analysed by using SPSS version 14.0 for Windows. Differences in proportions were compared using the Chisquare test and the significance level was set at $p \leq 0.05$. Predictors for seasonal and pandemic influenza vaccination were determined by multiple logistic regression analyses.

Results: With a response rate of 96.6\%, 906 individuals were enrolled and 868 (92.5\%) provided complete data. Seasonal influenza vaccination coverage was $13.7 \%(n=119)$. Only $43(14.2 \%)$ participants were vaccinated against pandemic influenza $\mathrm{A} / \mathrm{H} 1 \mathrm{~N} 1$, mostly having received both vaccines simultaneously, the seasonal and pandemic one. Job-related purposes $(44,37 \%)$, age $>64$ yrs $(25,21 \%)$ and recommendations of the family physician $(27,22.7 \%)$ were the most often reported reasons for being vaccinated. In the multiple logistic regression analyses of the pooled data increasing age $(\mathrm{OR}=1.03,95 \% \mathrm{Cl} 1.01-1.04)$, a business trip $(\mathrm{OR}=0.39,95 \% \mathrm{Cl} 0.17-0.92)$ and seasonal influenza vaccination in the previous winter seasons $(O R=12.91,95 \% \mathrm{Cl} 8.09-20.58)$ were independent predictors for seasonal influenza vaccination in 2009 or 2010.

Influenza vaccination recommended by the family doctor (327, 37.7\%), travel to regions with known high risk of influenza $(305,35.1 \%)$, and influenza vaccination required for job purposes $(233,26.8 \%)$ were most frequently mentioned to consider influenza vaccination.

Conclusions: Risk perception and vaccination coverage concerning seasonal and pandemic influenza was very poor among travellers to resource-limited destinations when compared to traditional at-risk groups. Previous access to influenza vaccination substantially facilitated vaccinations in the subsequent year. Information strategies about influenza should be intensified and include health professionals, e.g. family physicians, travel medicine practitioners and business enterprises.
\end{abstract}

* Correspondence: muetsch@ifspm.uzh.ch

2 Division of Epidemiology and Prevention of Communicable Diseases and World Health Organization (WHO) Collaborating Centre for Travellers' Health, Institute of Social- and Preventive Medicine, University of Zurich, Hirschengraben 84, 8001 Zurich, Switzerland

Full list of author information is available at the end of the article

() 2010 Pfeil et al; licensee BioMed Central Ltd. This is an Open Access article distributed under the terms of the Creative Commons At:10 Central tribution License (http://creativecommons.org/licenses/by/2.0), which permits unrestricted use, distribution, and reproduction in any
medium, provided the original work is properly cited. 


\section{Background}

Pandemic and seasonal influenza are still a challenging field of the public health system. Influenza - a mild to severe respiratory infection caused by RNA viruses of the family Orthomyxoviridae - is one of the most common vaccine-preventable disease in travellers. Worldwide, between 250 '000 and 500'000 deaths are estimated to be due to seasonal influenza infection each year [1]. Influenza is also responsible for tremendous economic costs both from admissions to hospital and loss of productivity [2]. Influenza affects all age groups and is usually self-limited. Common symptoms include acute fever, muscles pain, headache, cough and chills [3]. Special risk groups, such as very young children, the elderly and those suffering from chronic lung or heart diseases are at risk for serious influenza complications, e.g. bacterial pneumonia $[4,5]$. Influenza reaches peak prevalence in winter in the Northern hemisphere (Nov-Apr) - as well as in the Southern hemisphere (Apr-Oct) and circulates yearround in the tropics [6,7]. Seasonal influenza vaccination is an effective prevention strategy and is therefore routinely recommended for special risk groups [8,9]. Of note, the seasonal influenza vaccine recommendations of the U.S. Centres for Disease Control were recently expanded and include now about $80 \%$ of the population [10].

Influenza is known to be a quite frequent infection among travellers to tropical and subtropical destinations compared to other infections, e.g. vector-borne ones. About one of hundred travellers abroad gets infected [7]. The risk of infection depends on the travel destination and the season. Travellers crossing hemispheres may be confronted with different antigenic variants of the influenza virus. By returning home, the new variant may be transmitted to contact persons [11]. The first pandemic of the 21st century has highlighted the need for international influenza prevention strategies [12].

The objective of this study was to investigate the vaccination coverage as well as knowledge, attitudes and practices (KAP) regarding influenza vaccination among travellers to resource-limited countries to improve or adapt current preventive strategies.

\section{Methods}

Two cross-sectional surveys were conducted at the University of Zurich Centre for Travel' Health during January and February 2009 and January 2010, respectively. Selfadministered, anonymous questionnaires including 16 items were distributed to travellers waiting for pre-travel health advice. Participation was voluntary. Individuals above 17 years, understanding German or English, residing in Switzerland and planning to travel to a resourcelimited destination were included. Questions included demographic data (gender, age, nationality, education, profession), travel-related characteristics (destination country, duration of stay, influenza risk perception, previous travel health advice, travel purpose, travel costs) and general attitudes and practices towards influenza vaccination (vaccination coverage, reasons to be vaccinated, reasons to refuse vaccination, motivations to consider vaccination with options for multiple answers except for the vaccination coverage). In 2010, an additional question targeting the pandemic influenza $\mathrm{A} / \mathrm{H} 1 \mathrm{~N} 1$ vaccination coverage was included. The questionnaires were checked for completeness. A written letter of exempt was received by the Ethical Commission of the Canton of Zurich.

Statistical analyses were conducted by using SPSS $^{\circ}$ version 14.0 for Windows. Differences in proportions of demographics, travel-related data and attitudes and practices were compared using the Chi-square test. The significance level was set at $p \leq 0.05$. For the multiple logistic regression analysis the surveys were analysed as well as pooled dataset and each survey, CTH-2009 and CTH2010 , separately. The seasonal influenza vaccination was used as outcome and all demographic, travel-related and attitude- and practices-related factors were evaluated as independent predictors. Odds Ratios (OR) were determined by stepwise backward elimination of variables with $\mathrm{p}>0.150$. For sensitivity analyses, each dataset of the CTH studies, 2009 and 2010, was analysed separately and additionally, predictors for pandemic influenza vaccination were determined by multiple logistic regression analyses.

\section{Results}

\section{Study population}

From a total of 938 eligible individuals, 868 (92.5\%) were included in the analysis (Figure 1). Overall, 479 (55.2\%) were females and $389(44.8 \%)$ males. The great majority of participants (503, 57.9\%) were between 18 and 35 years old with a median age of 32 years (range $18-84$ yrs). Only $46(5.3 \%)$ responders were above 64 years of age. In general, participants were highly educated with 480 (55.3\%) being university graduates. Overall, the characteristics of participants planning to travel to resource-limited destinations are presented in Table 1.

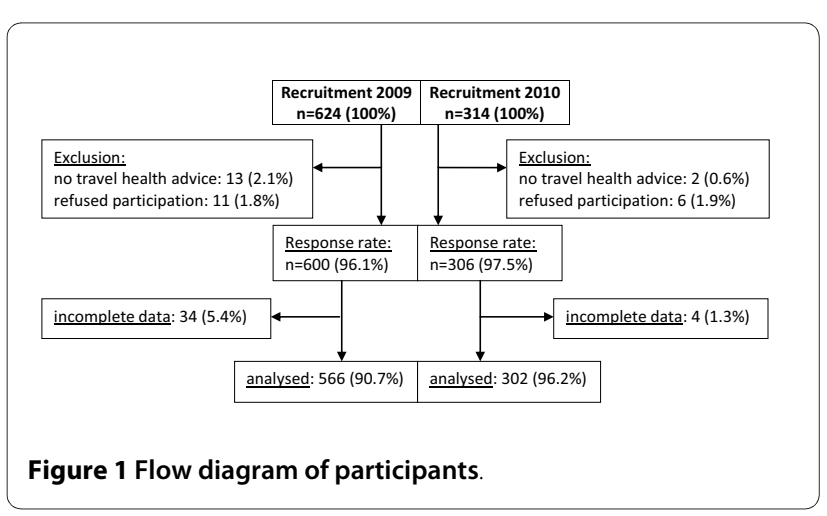


Table 1: Characteristics of participants planning to travel to resource-limited destinations

\begin{tabular}{|c|c|c|c|c|c|}
\hline \multicolumn{2}{|c|}{ Characteristics } & \multirow{2}{*}{$\begin{array}{l}\text { All }(\mathbf{n}=\mathbf{8 6 8}) \\
479(55.2 \%)\end{array}$} & \multirow{2}{*}{$\begin{array}{c}\text { CTH } 2009(\mathbf{n}=\mathbf{5 6 6}) \\
313(55.3 \%)\end{array}$} & \multirow{2}{*}{$\begin{array}{c}\text { CTH } 2010(\mathbf{n}=\mathbf{3 0 2}) \\
166(55 \%)\end{array}$} & \multirow{2}{*}{$\begin{array}{l}\text { p-value } \\
p=0.925\end{array}$} \\
\hline Gender: & female & & & & \\
\hline & male & $389(44.8 \%)$ & $253(44.7 \%)$ & $136(45 \%)$ & \\
\hline \multirow[t]{2}{*}{ Age (yrs): } & mean & 37 & 37 & 37 & $p=1.000$ \\
\hline & median (range) & $32(18-84)$ & $32(18-81)$ & $32(18-84)$ & \\
\hline \multirow[t]{4}{*}{ Age-groups: } & $18-35$ yrs & $503(57.9 \%)$ & $324(57.2 \%)$ & 179 (59.3\%) & $p=0.564$ \\
\hline & $36-50$ yrs & $204(23.5 \%)$ & $142(25.1 \%)$ & $62(20.5 \%)$ & $p=0.131$ \\
\hline & $51-64$ yrs & $115(13.2 \%)$ & $74(13.1 \%)$ & $41(13.6 \%)$ & $p=0.835$ \\
\hline & $>64$ yrs & $46(5.3 \%)$ & $26(4.6 \%)$ & $20(6.6 \%)$ & $p=0.204$ \\
\hline \multirow[t]{3}{*}{ Educational level: } & prim./sec. school & $20(2.3 \%)$ & $13(2.3 \%)$ & $7(2.3 \%)$ & \\
\hline & traineeship/A-level & $368(42.4 \%)$ & $241(42.6 \%)$ & $127(42.1 \%)$ & \\
\hline & university & $480(55.3 \%)$ & $312(55.1 \%)$ & $168(55.6 \%)$ & $p=0.989$ \\
\hline \multirow[t]{5}{*}{ Travel continent: } & Africa & $243(28 \%)$ & $151(26.7 \%)$ & $92(30.5 \%)$ & $p=0.237$ \\
\hline & Latin America & $273(31.5 \%)$ & $198(35 \%)$ & $75(24.8 \%)$ & $p=0.002$ \\
\hline & Asia & $331(38.1 \%)$ & $208(36.7 \%)$ & $123(40.7 \%)$ & $p=0.250$ \\
\hline & SE Europe & $6(0.7 \%)$ & $2(0.4 \%)$ & $4(1.3 \%)$ & $p=0.744$ \\
\hline & Oceania & $15(1.7 \%)$ & $7(1.2 \%)$ & $8(2.6 \%)$ & $p=0.128$ \\
\hline \multirow[t]{4}{*}{ Duration of stay (days): } & 1 - 7 days & $29(3.3 \%)$ & $18(3.2 \%)$ & $11(3.6 \%)$ & \\
\hline & 8 - 14 days & $183(21.1 \%)$ & $112(19.8 \%)$ & $71(23.5 \%)$ & \\
\hline & 15 - 28 days & $342(39.4 \%)$ & $233(41.2 \%)$ & 109 (36.1\%) & $p=0.432$ \\
\hline & $>28$ days & $314(36.2 \%)$ & $203(35.9 \%)$ & $111(36.8 \%)$ & \\
\hline \multirow{3}{*}{$\begin{array}{l}\text { Perceived risk of influenza } \\
\text { at destination: }\end{array}$} & high & $72(8.3 \%)$ & $42(7.4 \%)$ & $30(9.9 \%)$ & \\
\hline & low & $515(59.3 \%)$ & $338(59.7 \%)$ & $177(58.6 \%)$ & $p=0.436$ \\
\hline & no idea & $281(32.4 \%)$ & $186(32.9 \%)$ & $95(31.5 \%)$ & \\
\hline \multirow{3}{*}{$\begin{array}{l}\text { Source of travel health } \\
\text { information*: }\end{array}$} & internet & $340(39.2 \%)$ & $211(37.3 \%)$ & $129(42.7 \%)$ & $p=0.118$ \\
\hline & family doctor & $111(12.8 \%)$ & $74(13.1 \%)$ & $37(12.3 \%)$ & $p=0.730$ \\
\hline & family/friends & $75(8.6 \%)$ & $50(8.8 \%)$ & $25(8.3 \%)$ & $p=0.781$ \\
\hline \multirow[t]{3}{*}{ Purpose of the journey: } & holidays & $695(80.1 \%)$ & $448(79.2 \%)$ & $247(81.8 \%)$ & $p=0.354$ \\
\hline & $\mathrm{VFR}^{* *}$ & $107(12.3 \%)$ & $73(12.9 \%)$ & $34(11.3 \%)$ & $p=0.484$ \\
\hline & business & $92(10.6 \%)$ & $61(10.8 \%)$ & $31(10.3 \%)$ & $p=0.815$ \\
\hline \multirow[t]{4}{*}{ Travel expenses (CHF): } & $0-4999$ & $564(65 \%)$ & $378(66.8 \%)$ & $186(61.6 \%)$ & \\
\hline & $5000-9999$ & $197(22.7 \%)$ & $122(21.6 \%)$ & $75(24.8 \%)$ & \\
\hline & $10000-15000$ & $49(5.6 \%)$ & $35(6.2 \%)$ & $14(4.6 \%)$ & $p=0.091$ \\
\hline & $>15000$ & $31(3.6 \%)$ & $15(2.7 \%)$ & $16(5.3 \%)$ & \\
\hline
\end{tabular}


Table 1: Characteristics of participants planning to travel to resource-limited destinations (Continued)

\begin{tabular}{|c|c|c|c|c|}
\hline Seasonal vaccination coverage & $119(13.7 \%)$ & $65(11.5 \%)$ & $54(17.9 \%)$ & $p=0.009$ \\
\hline Pandemic vaccination coverage & $43(14.2 \%)$ & na & $43(14.2 \%)$ & na \\
\hline
\end{tabular}

\section{Travel characteristics}

The majority reported travel to South America (188, $21.7 \%)$, followed by South-east Asia (170, 19.6\%) and South-central Asia (135, 15.6\%). Most frequently countries planned to visit included India $(125,14.4 \%)$ and Thailand (87, 10\%). Most travellers stayed at their destination between 15 days to four weeks (342, 39.4\%). Only $72(8.3 \%)$ travellers estimated their destination as at high risk for influenza infection, of these 17 (23.6\%) were vaccinated against seasonal influenza. Only 111 (12.8\%) responders were informed by their family physicians in advance, web-based information was consulted by 340 travellers (39.2\%). The great majority, 695 (80.1\%), included holiday travellers, 107 (12.3\%) were visiting friends or relatives (VFR) and every tenth $(92,10.6 \%)$ was a business traveller.

\section{Vaccination coverage}

A total of 119 (13.7\%) participants were vaccinated against seasonal influenza, 43 (14.2\%) against pandemic influenza in 2010 and 25 (8.3\%) have received both influenza vaccinations. The great majority $(630,72.6 \%)$ has never received an influenza vaccination in their life. In the multiple logistic regression analysis, increasing age $(\mathrm{OR}=1.03,95 \%$ CI $1.01-1.04)$ and seasonal influenza vaccination in the previous winter seasons $(\mathrm{OR}=12.91$, 95\% CI 8.09 - 20.58) were significant predictors for being vaccinated against seasonal influenza (Table 2). Business travellers $(\mathrm{OR}=0.39,95 \% \mathrm{CI} 0.17$ - 0.92) were significantly less often vaccinated than other traveller groups. The same independent factors were determined when analysing each survey, CTH-2009 and CTH-2010, separately. Having received the pandemic influenza vaccination was significantly associated with having received the seasonal influenza vaccination in winter 2009/2010 (OR $=10.86$, 95\% CI 5.11 - 23.09).

\section{KAP on seasonal influenza vaccination}

Of all vaccinated participants, 44 (37\%) declared to be vaccinated for business reasons and $25(21 \%)$ due to age (Table 3$)$. Only $10(8.4 \%)$ responders reported to be vaccinated for their journey. Travellers remained mostly unvaccinated $(326,43.5 \%)$ because they felt not at risk, 144 (19.2\%) have missed any recommendation by their family physician and a substantial proportion (172, 23\%) did not see any relevance for being vaccinated. Often mentioned as "other reasons" for being unvaccinated (108, 14.3\%) included items like: rare/never affected by influenza $(43,5.7 \%)$, vaccine is not effective enough (34, $4.5 \%)$ and bad experiences with vaccine/side-effects of vaccine $(31,4.1 \%)$. Most travellers would consider vaccination if they would feel in bad general health (408, 47\%), followed by a recommendation of the family physician (327, 37.7\%) and travel to regions with known high risk of influenza $(305,35.1 \%)$. Of note, $65(7.5 \%)$ intended to refuse influenza vaccination at any time.

\section{Discussion}

Travel as risk factor for an influenza infection is poorly established among international travellers when regarding the low vaccination coverage as well as the low selfperceived travel-associated risk estimates. Of note, previous influenza vaccinations facilitated receiving an influenza vaccination in the following year by about 13 times. Therefore, easy access to the influenza vaccine is important. High media coverage was not considered sufficient to increase the vaccination rate substantially as is indicated by the low increase of the vaccination coverage between the two surveys in 2009 and 2010 and also by the low pandemic influenza vaccination coverage of only $14.2 \%$. Therefore, multiple efforts need to complement one another including information strategies provided by family physicians and travel medicine practitioners, but also job- and age-related activities need to be considered.

Our sample of travellers is comparable to other studies performed at our Centre for Travel' Health [7] with respect to the age distribution, educational level and travel duration. Inherent limitations include a selection bias: Frequently visited destinations such as the Middle East, North Africa and the Caribbean are underrepresented as travellers to those destinations generally do not consider a pre-travel health consultation as indicated [11] but destinations with higher risk for faecal-orally transmitted infectious diseases, such as TD or bacterial meningitis, are well represented, such as e.g. India and SubSaharan countries. Therefore, our sample may represent a best practice sample. The fact, that the high proportion of university graduates indicates a health literate population may result in an even overestimated risk perception as well as influenza vaccination coverage. All data collections relied on self-reported information. Hence, the results of the studies might be limited by a potential bias 
Table 2: Predictors of seasonal influenza vaccination among travellers to resource-limited destinations determined by multiple logistic regression analysis

\begin{tabular}{|c|c|c|c|}
\hline Variable & $\begin{array}{c}\text { Univariate OR } \\
(95 \% \mathrm{CI}) \mathrm{N}=\mathbf{8 6 8}\end{array}$ & $\begin{array}{l}\text { Multivariate OR } \\
(95 \% \mathrm{Cl}) \mathrm{N}=\mathbf{8 6 8}\end{array}$ & $\begin{array}{l}\text { Final Model OR } \\
(95 \% \mathrm{Cl}) \mathrm{N}=\mathbf{8 6 8}\end{array}$ \\
\hline Gender & $1.05(0.71-1.56)$ & $1.10(0.69-1.76)$ & $1.11(0.70-1.75)$ \\
\hline Age (yrs) & $1.05(1.03-1.06)$ & $1.03(1.01-1.04)$ & $1.03(1.01-1.04)$ \\
\hline Nationality & $0.98(0.92-1.04)$ & & \\
\hline Educational level & $0.97(0.68-1.38)$ & & \\
\hline Travel continent & $0.95(0.76-1.20)$ & & \\
\hline Destination by $\mathrm{N}$ vs. S hemisphere & $1.49(1.01-2.19)$ & $1.47(0.93-2.35)$ & \\
\hline Duration of stay (d) & $0.74(0.59-0.93)$ & $0.74(0.56-0.99)$ & $0.78(0.59-1.03)$ \\
\hline Perceived risk of influenza at destination & $0.74(0.54-1.03)$ & $0.85(0.52-1.26)$ & \\
\hline \multicolumn{4}{|l|}{ Travel health advice by: } \\
\hline family doctor & $2.05(1.25-3.36)$ & $1.50(0.78-2.89)$ & \\
\hline travel clinic & $1.25(0.84-1.86)$ & & \\
\hline internet & $0.73(0.48-1.09)$ & $0.79(0.46-1.34)$ & \\
\hline travel agency & $0.57(0.24-1.34)$ & & \\
\hline family or friends & $0.85(0.41-1.75)$ & & \\
\hline No advice & $0.67(0.41-1.09)$ & $0.78(0.42-1.46)$ & \\
\hline \multicolumn{4}{|l|}{ Travel purpose: } \\
\hline holidays & $1.27(0.76-2.12)$ & & \\
\hline business & $0.57(0.27-1.21)$ & $0.40(0.17-0.97)$ & $0.39(0.17-0.92)$ \\
\hline$V_{F R}^{*}$ & $1.12(0.64-1.99)$ & & \\
\hline education & $0.58(0.23-1.47)$ & & \\
\hline others & $0.42(0.10-1.80)$ & & \\
\hline Travel expenses & $1.35(1.08-1.69)$ & $1.14(0.84-1.56)$ & \\
\hline Previous seasonal influenza vaccination & $14.39(9.18-22.58)$ & $12.42(7.71-20.01)$ & $12.91(8.09-20.58)$ \\
\hline
\end{tabular}

such as disclosure bias, although self-report of influenza vaccination status has been found to be reliable when checked against medical record documentation [13].

Most seasonal influenza activity occurs during November to April on the Northern hemisphere and vaccination is usually administered between October and November. Therefore, travellers visiting the opposite hemisphere have to be counselled accordingly and the seasonal influ- enza vaccine also for the Southern hemisphere has to be available as there is year-round influenza activity in tropical and subtropical areas.

\section{Conclusions}

Risk perception and vaccination coverage regarding seasonal and pandemic influenza was very poor among European travellers to resource-limited destinations 
Table 3: Attitudes and practices regarding influenza vaccination among travellers to resource-limited destinations

\begin{tabular}{|c|c|c|c|c|}
\hline $\begin{array}{l}\text { Reasons for getting vaccinated (only vaccinated } \\
\text { participants) }\end{array}$ & All $(n=119)$ & CTH $09(n=65)$ & CTH $10(n=54)$ & p-value \\
\hline Because it is required for my job & $44(37 \%)$ & $26(40 \%)$ & $18(33.3 \%)$ & $p=0.453$ \\
\hline My family doctor advised me to do it & $27(22.7 \%)$ & $18(27.7 \%)$ & $9(16.7 \%)$ & $p=0.153$ \\
\hline Because of my age & $25(21 \%)$ & $12(18.5 \%)$ & $13(24.1 \%)$ & $p=0.454$ \\
\hline Because it is free & $8(6.7 \%)$ & $6(9.2 \%)$ & $2(3.7 \%)$ & $p=0.231$ \\
\hline Because of the arranged journey & $10(8.4 \%)$ & $2(3.1 \%)$ & $8(14.8 \%)$ & $p=0.022$ \\
\hline Because of media attention on SARS and avian flu & $0(0 \%)$ & $0(0 \%)$ & na & na \\
\hline Because of media attention on pandemic 2009 & $2(3.7 \%)$ & na & $2(3.7 \%)$ & na \\
\hline \multirow{2}{*}{$\begin{array}{l}\text { Reasons for not getting vaccinated (unvaccinated } \\
\text { participants) }\end{array}$} & All $(n=749)$ & Стн 09 & CTH 10 & p-value \\
\hline & & $(n=501)$ & $(n=248)$ & \\
\hline I made bad experiences with a previous flu vaccine & $31(4.1 \%)$ & $23(4.6 \%)$ & $8(3.2 \%)$ & $p=0.377$ \\
\hline The vaccine is not effective enough & $34(4.5 \%)$ & $30(6.0 \%)$ & $4(1.6 \%)$ & $p=0.007$ \\
\hline I did not get any recommendations & $144(19.2 \%)$ & $114(22.8 \%)$ & $30(12.1 \%)$ & $P<0.001$ \\
\hline I am not at risk & $326(43.5 \%)$ & $197(39.3 \%)$ & $129(52 \%)$ & $p=0.001$ \\
\hline It is not important & $172(23 \%)$ & $115(23 \%)$ & $57(23 \%)$ & $p=1.000$ \\
\hline Encouraging factors for vaccination next season & All $(n=868)$ & CTH 09(n = 566) & CTH 10(n = 302) & p-value \\
\hline If I would feel in bad general health & $408(47 \%)$ & $260(45.9 \%)$ & $148(49 \%)$ & $p=0.388$ \\
\hline If my family doctor recommended it to me & $327(37.7 \%)$ & $210(37.1 \%)$ & $117(38.7 \%)$ & $p=0.635$ \\
\hline Travel to regions with high risk of influenza & $305(35.1 \%)$ & $203(35.9 \%)$ & $102(33.8 \%)$ & $p=0.539$ \\
\hline Because of age & $215(24.8 \%)$ & $146(25.8 \%)$ & $69(22.8 \%)$ & $p=0.338$ \\
\hline Job requirement & $233(26.8 \%)$ & $143(25.3 \%)$ & $90(29.8 \%)$ & $p=0.151$ \\
\hline Ongoing flu season & $87(10 \%)$ & $59(10.4 \%)$ & $28(9.3 \%)$ & $p=0.590$ \\
\hline I would never be vaccinated & $65(7.5 \%)$ & $40(7.1 \%)$ & $25(8.3 \%)$ & $p=0.518$ \\
\hline
\end{tabular}

CTH: Centre for Travel Health

Multiple answers were possible. The $p$-value was determined with Chi-square test, statistical significance was set at $p \leq 0.05$.

when compared to traditional at-risk groups. Age and previous influenza vaccination were the best predictors for considering seasonal influenza vaccination in our population. Communication strategies about influenza should be intensified and should include all health professionals, e.g. family physicians and travel medicine practitioners, but also business enterprises.

\section{Competing interests}

The authors declare that they have no competing interests.

\section{Authors' contributions}

TDS, MM and CH conceived and supervised the study. AP performed all data collection and data analysis and drafted the manuscript. MM participated in designing the study and the questionnaire and organised access to the data of the airport-study. All authors have read and approved the final manuscript.
Acknowledgements

We thank all participating travellers and we acknowledge the technical assistance of Patricia Blank.

\section{Author Details}

1 Institute of Social- and Preventive Medicine, University of Zurich,

Hirschengraben 84, 8001 Zurich, Switzerland, 2Division of Epidemiology and Prevention of Communicable Diseases and World Health Organization (WHO) Collaborating Centre for Travellers' Health, Institute of Social- and Preventive Medicine, University of Zurich, Hirschengraben 84, 8001 Zurich, Switzerland and ${ }^{3}$ Division of Medical Economics, Institute of Social- and Preventive

Medicine, University of Zurich, Hirschengraben 84, 8001 Zurich, Switzerland

Received: 30 October 2009 Accepted: 7 July 2010

Published: 7 July 2010

\section{References}

1. Marti F, Steffen R, Mutsch M: Influenza vaccine: a travelers' vaccine? Expert Rev Vaccines 2008, 7(5):679-687. 
2. Ruf BR, Szucs TD: Reducing the Burden of Influenza-Associated Complications with Antiviral Therapy. Infection 2009, 37(3):186-196.

3. Taubenberger JK, Morens DM: The Pathology of Influenza Virus Infections. Annu Rev Pathol 2008, 3:499-522.

4. Freedman DO, Leder K: Influenza: Changing approaches to prevention and treatment in travelers. J Travel Med 2005, 12:36-44.

5. Nicoll A, Ciancio BC, Tsolova S, Blank PR, Yilmaz C: The scientific basis for offering seasonal influenza immunisation to risk groups in Europe. Eurosurveill 2008, 13(43):1-8.

6. Shaman J, Pitzer VE, Viboud C, et al: Absolute Humidity and the Seasonal Onset of Influenza in the Continental United States. PLoS Biology 2010, 8(2):e1000316.

7. Mutsch M, Tavernini M, Marx A, Gregory V, Lin YP, Hay AJ, Tschopp A Steffen R: Influenza virus infection in travelers to tropical and subtropical countries. Clin Infect Dis 2005, 40:1282-1287.

8. Lee CY, Naguel C, Gyurech D, Duvoisin N, Schilling J: Awareness of vaccination status and its predictors among working people in Switzerland. BMC Public Health 2003, 3:18.

9. Blank PR, Schwenkglenks M, Szucs TD: Influenza vaccination coverage rates in five European countries during season 2006/2007 and trends over six consecutive seasons. BMC Public Health 2008, 8:272.

10. Centers for Disease Control and Prevention (CDC) - CDC's Advisory Committee on Immunization Practices (ACIP) Recommends Universal Annual Influenza Vaccination [http://www.cdc.gov/media/pressrel/ 2010/r100224.htm]. (Access at [April 22nd, 2010])

11. van Herck K, Castelli F, Zuckerman J, Nothdurft H, van Damme P, Dahlgren A, Gargalianos P, Lopéz-Vélez R, Overbosch D, Caumes E, Walker E, Gisler S, Steffen R: Knowledge, attitudes and practices in travel-related infectious diseases: The European Airport Survey. J Travel Med 2004, 11:3-8.

12. Sullivan SJ, Jacobson RM, Dowdle WR, Poland GA: 2009 H1N1 Influenza. Mayo Clin Proc 2010, 85(1):64-76.

13. Endrich MM, Blank PR, SzUCS TD: Influenza vaccination uptake and socioeconomic determinants in 11 European countries. Vaccine 2009, 27:4018-402.

\section{Pre-publication history}

The pre-publication history for this paper can be accessed here: http://www.biomedcentral.com/1471-2458/10/402/prepub

doi: 10.1186/1471-2458-10-402

Cite this article as: Pfeil et al., A cross-sectional survey to evaluate knowledge, attitudes and practices (KAP) regarding seasonal influenza vaccination among European travellers to resource-limited destinations BMC Public Health 2010, 10:402

\section{Submit your next manuscript to BioMed Central} and take full advantage of:

- Convenient online submission

- Thorough peer review

- No space constraints or color figure charges

- Immediate publication on acceptance

- Inclusion in PubMed, CAS, Scopus and Google Scholar

- Research which is freely available for redistribution

Submit your manuscript at www.biomedcentral.com/submit
C Biomed Central 